\title{
Observer-Based State Feedback for Enhanced Insulin Control of Type ' $I$ ' Diabetic Patients
}

\author{
Ali Hariri ${ }^{1}{ }^{*}$ and Le Yi Wang ${ }^{2}$ \\ ${ }^{I}$ DTE Energy, One Energy Plaza, Detroit, Michigan, 48226 \\ ${ }^{2}$ ECE Department, Wayne State University, Detroit, Michigan, 48202
}

\begin{abstract}
During the past few decades, biomedical modeling techniques have been applied to improve performance of a wide variety of medical systems that require monitoring and control. Diabetes is one of the most important medical problems. This paper focuses on designing a state feedback controller with observer to improve the performance of the insulin control for type 'I' diabetic patients. The dynamic model of glucose levels in diabetic patients is a nonlinear model. The system is a typical fourth-order single-input-single-output state space model. Using a linear time invariant controller based on an operating condition is a common method to simplify control design. On the other hand, adaptive control can potentially improve system performance. But it increases control complexity and may create further stability issues. This paper investigates patient models and presents a simplified control scheme using observer-based feedback controllers. By comparing different control schemes, it shows that a properly designed state feedback controller with observer can eliminate the adaptation strategy that the Proportional-Integral-Derivative (PID) controllers need to improve the control performance. Control strategies are simulated and their performance is evaluated in MATLAB and Simulink.
\end{abstract}

Keywords: Biomedical modeling, insulin, diabetes, feedback controller, observer, adaptation.

\section{INTRODUCTION}

Insulin is a hormone that is necessary for converting the blood sugar, or glucose, into usable energy. The human body maintains an appropriate level of insulin. Diabetes is caused by lack of insulin in the body. There are two major types of diabetes, called type 'I' and type 'II' diabetes. Type 'I' diabetes are called Insulin Dependent Diabetes Mellitus (IDDM), or Juvenile Onset Diabetes Mellitus (JODM). Type 'II' diabetes are known as Non-Insulin Dependent Diabetes Mellitus (NIDDM) or Adult-Onset Diabetes (AOD) [1-7]. The lifestyles of type 'I' diabetes are often severely affected by the Consequences of the disease. Because of the insulin producing B-cells of the pancreas are destroyed, patients typically regulate glucose manually. The patient is totally dependent on an external source of insulin to be infused at an appropriate rate to maintain blood glucose concentration. Mishandling this task, potentially lead to a number of serious health problems including heart and blood vessel disease, kidney disease, blindness. Deviations below the basal glucose levels (hypoglycemic deviations) are considerably more dangerous in the short term than positive (hyperglycemic) deviations, although both types of deviations are undesirable [8, 9]. Large efforts are undertaken in pharmacology and biomedical engineering to control glucose concentration by proper insulin dosing [10].

The insulin infusion rate to a diabetic patient can be administrated based on the glucose (sugar) level inside the body. Over the years many mathematical models have been

*Address correspondence to this author at the DTE Energy, One Energy Plaza, Detroit, Michigan, 48226; Tel: 313-235-5188; Fax: 313-235-8052;

E-mail: hariria@dteenergy.com developed to describe the dynamic behavior of human glucose-insulin systems. The most commonly used model is the minimal model introduced by Bergman [6, 11-16]. The minimal model consists of a set of three differential equations with unknown parameters. Since diabetic patients differ dramatically due to variations of their physiology and pathology characteristics, the parameters of the minimal model are significantly different among patients. Based on such models, a variety of control technologies have been applied to glucose/insulin control problems [17-20]. Therefore, the closed loop control techniques are developed to maintain physiological glucose level [10].

This paper studies benefits of using simplified control strategies in improving performance of insulin control for type 'I' diabetic patients. In the previous paper, "Identification and Low-Complexity Regime-Switching Insulin Control of Type 'I' Diabetic Patients', we studied adaptive Proportional-Integral-Derivative (PID) control strategies for type I diabetes. This paper investigates patient models and presents a simplified control scheme using state feedback controllers. The design of the state feedback controller is based on the pole placement method using the Ackermann's Formula. By comparing the design of the state feedback controller to that of the PID controller in gainscheduled adaptation strategies, we show that the state feedback can improve the system performance and simplify the complexity of the control system. These findings lead to a control scheme that utilizes a non-adaptive observer-based state feedback controller.

Many methods and techniques have been investigated, tested, and studied for controlling the glucose level in type ' $I$ ' diabetes patients. Research in this field has always been 
Table 1. Blood Glucose Levels Chart

\begin{tabular}{|c|c|c|c|}
\hline \multirow{2}{*}{$\begin{array}{c}\text { Person's } \\
\text { Category }\end{array}$} & \multicolumn{2}{|c|}{ Fating State } & Postprandial \\
\cline { 2 - 4 } & $\begin{array}{c}\text { Glucose } \\
\text { Minimum } \\
\text { Value } \\
\text { (mg/dl) }\end{array}$ & $\begin{array}{c}\text { Glucose } \\
\text { Maximum } \\
\text { Value } \\
\text { (mg/dl) }\end{array}$ & $\begin{array}{c}\mathbf{2 - 3} \text { Hours } \\
\text { after Eating } \\
\text { (mg/dl) }\end{array}$ \\
\hline \hline Hypoglycemia & - & $<59$ & $<60$ \\
\hline Early hypoglycemia & 60 & 79 & $60-70$ \\
\hline Normal & 80 & 100 & $<140$ \\
\hline Early diabetes & 101 & 126 & $140-200$ \\
\hline Diabetic & $>126$ & - & $>200$ \\
\hline
\end{tabular}

model-based and has moved from the development of the structure of a model of glucose and insulin dynamics stepping towards model parameter estimation and model personalisation to each single patient's requirements [21]. Fisher [18] used the glucose insulin minimal model to design a semi-closed loop insulin infusion algorithm based on three hourly plasma glucose sampling. The study was concentrated on the glucose level, and did not take in consideration some factors such as free plasma insulin concentration and the rate at which insulin was produced as the level of glucose rises. Furler [19] modified the glucose insulin minimal model by removing the insulin secretion and adding insulin antibodies to the model. The algorithm calculated the insulin infusion rate as a function of the measured plasma glucose concentration. The linear interpolation was used to find the insulin rate. The algorithm neglected some variations in insulin concentration and other model variables. Ibbini, Masadeh and Amer [20] tested the glucose minimal model to design a semi closed-loop optimal control system to control the glucose level in diabetes patients.

\section{MODEL STRUCTURES}

The level of the glucose inside the human being body changes significantly in response to food intake and other physiological and environment conditions, it is necessary to derive mathematics models to capture such dynamics for control design [11-13, 22-24]. To simplify the model for control design, a common practice is to locally linearize the minimal model under a given operating condition.

The insulin enters or exits the interstitial insulin compartment at a rate that is proportional to the difference $i(t)-i_{b}$ of plasma insulin $i(t)$ and the basal insulin level $i_{b}$ $[25,26]$. If the level of the insulin in the plasma is below the insulin basal level, insulin exits the interstitial insulin compartment. When the level of insulin in the plasma is above the insulin basal level, insulin enters the interstitial insulin compartment. On the other hand, glucose enters or exits the plasma compartment at a rate that is proportional to the difference $g(t)-g_{b}$ of the plasma glucose level $g(t)$ and the basal glucose level $g_{b}$. When the level of glucose in the plasma is below the glucose basal level, the glucose exits the plasma compartment. When the level of glucose in the plasma is above the glucose basal level, glucose enters the glucose compartment. The normal range of blood glucose concentration should be maintained within narrow limits throughout the day: 70-140 mg/dl, lower in the morning and higher after the meals $[27,28]$.
For most normal persons the glucose levels are between $80 \mathrm{mg} / \mathrm{dl}$ and $100 \mathrm{mg} / \mathrm{dl}$ in a fasting state, which is before eating or drinking anything for at least 8 hours. Table $\mathbf{1}$ shows the glucose levels for different people categories with the minimum and maximum value of the glucose level for each category [29]. After eating, the glucose level rises above the normal level and should fall back to the original starting point within 2 to 3 hours. If the glucose level does not fall down, the person is classified as Diabetic or at the early diabetes stage. However the glucose level should not fall below $60 \mathrm{mg} / \mathrm{dl}$ [30] as this is typically the symptom of hypoglycemia

The minimal model has been developed and tested on healthy subjects, whose insulin is released by pancreas depending on the actual blood glucose concentration [21]. The minimal model consists of two parts: the minimal model of glucose disappearance, $(g$ and $v$ ), and the minimal model of insulin kinetics, $(i)$

$$
\begin{aligned}
& \dot{g}(t)=-\left[P_{1}+v(t)\right] g(t)+P_{1} g_{b} \\
& \dot{v}(t)=-P_{2} v(t)+P_{3}\left(i(t)-i_{b}\right) \\
& i(t)=-n i(t)+\gamma[g(t)-h] t
\end{aligned}
$$

where $g(t)(\mathrm{mg} / \mathrm{dl})$ is the blood glucose level in plasma; $i(t)$ $(\mu \mathrm{U} / \mathrm{ml})$ is the insulin concentration level in plasma; $v(t)$ $\left(\min ^{-1}\right)$ is the variable which is proportional to the insulin in the remote compartment, $g_{b}(\mathrm{mg} / \mathrm{dl})$ is the basal blood glucose level in plasma; $i_{b}(\mu \mathrm{U} / \mathrm{ml})$ is the basal insulin level in plasma; $t$ ( $\mathrm{min})$ is the time interval from the glucose injection. The initial conditions of the above differential equations are: $g(0)=g_{0}, v(0)=0, i(0)=i_{0}$.

The model parameters carry some physiological meanings that can be summarized as follows. $P_{1}\left(\mathrm{~min}^{-1}\right)$ describes the "glucose effectiveness" which represents the ability of blood glucose to enhance its own disposal at the basal insulin level. $P_{2}\left(\mathrm{~min}^{-1}\right)$ describes the decreasing level of insulin action with time. $P_{3}\left(\mathrm{~min}^{-2}(\mu \mathrm{U} / \mathrm{ml})^{-1}\right)$ describes the rate in which insulin action is increased as the level of insulin deviates from the corresponding baseline. $\gamma$ $\left((\mu \mathrm{U} / \mathrm{ml})(\mathrm{mg} / \mathrm{dl})^{-1} \mathrm{~min}^{-1}\right)$ denotes the rate at which insulin is produced as the level of glucose rises above a "target glycerin" level. $n\left(\mathrm{~min}^{-1}\right)$ represents fractional insulin clearance. $h(\mathrm{mg} / \mathrm{dl})$ is the pancreatic "target glycemia" level. $g_{0}(\mathrm{mg} / \mathrm{dl})$ is the theoretical glucose concentration in plasma extrapolated to the time of glucose injection $t=0,[11-13$, 31]. $i_{0}(\mu \mathrm{U} / \mathrm{ml})$ is the theoretical plasma insulin concentration at $t=0 . \mu \mathrm{U} / \mathrm{ml}$ is the conventional unit to measure the insulin level and has the following conversion: 1 microunit $/$ milliliter $=6$ picomole/liter, $(1 \mu \mathrm{U} / \mathrm{ml}=6 \mathrm{pmol} / \mathrm{l}),[32$, 33]. $P_{1}, P_{2}, P_{3}, n, \gamma, h, g_{0}$ and $i_{0}$ are the model parameters. A fourth differential equation will be added to the set of the minimal model equations to represent a first-order pump dynamics

$$
w(t)=\frac{1}{a}(-w(t)+u(t))
$$

where $w(t)$ is the infusion rate, $u(t)$ is the input command, and $a$ is the time constant of the pump. 


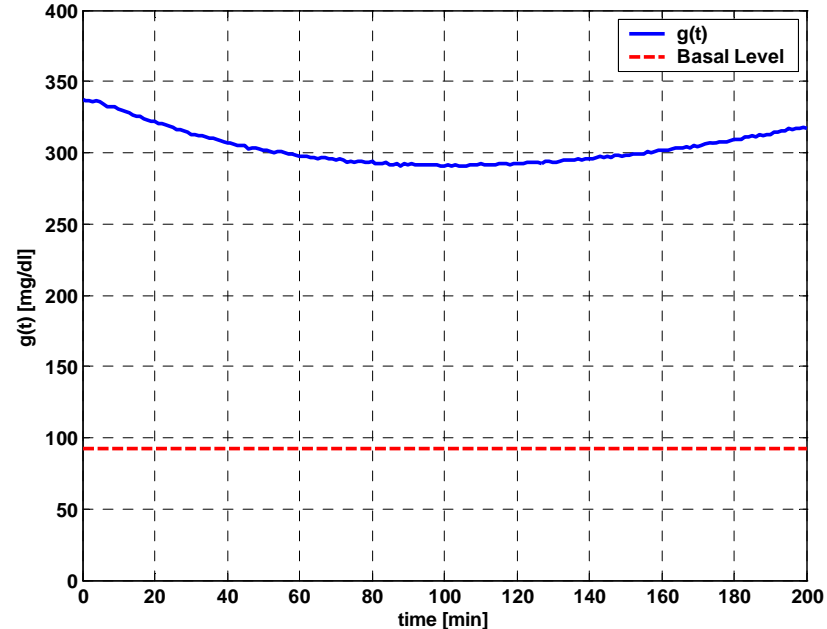

Fig. (1). Simulated glucose level $g(t)$ for diabetic patient.

Define

$x_{1}(t)=g(t), x_{2}(t)=v(t), x_{3}(t)=i(t), x_{4}(t)=w(t)$

then the above equations become

$x_{1}=-P_{1} x_{1}(t)-x_{1}(t) x_{2}(t)+P_{1} g_{b}$

$x_{2}=-P_{2} x_{2}(t)+P_{3} x_{3}(t)-P_{3} i_{b}$

$\dot{x}_{3}=\gamma t x_{1}(t)-n x_{3}(t)+x_{4}(t)-\gamma h t$

$\dot{x}_{4}=-\frac{1}{a} x_{4}(t)+\frac{1}{a} u(t)$

This above system is nonlinear due to the presence of the nonlinear term $x_{1}(t) * x_{2}(t)$. The Jacobian Matrices $\left(J_{x}\right.$ and $\left.J_{u}\right)$ of the mathematical model at the equilibrium point $\left(x_{0}, u_{0}\right)$ can be derived as

$$
J_{x}=\left[\begin{array}{cccr}
-P_{1}-x_{2} & -x_{1} & 0 & 0 \\
0 & -P_{2} & P_{3} & 0 \\
\gamma t & 0 & -n & 1 \\
0 & 0 & 0 & -\frac{1}{a}
\end{array}\right]_{x=x_{0}, u=u_{0}} \text { and }
$$$$
J_{u}=\left[\begin{array}{c}
0 \\
0 \\
0 \\
\frac{1}{a}
\end{array}\right]_{x=x_{0}, u=u_{0}}
$$

The following are the parameters values of a diabetic patient: $P_{1}=0, P_{2}=0.81 / 100, P_{3}=4.01 / 1000000, i_{0}=192$, $g_{0}=337, \gamma=2.4 / 1000, h=93, n=0.23, a=2, g_{b}=99, i_{b}=$ 8 [11-13]. These values are substituted in the patient dynamic system and the simulation was run. The result of the simulation is shown in Fig. (1). By examining Fig. (1), it can be clearly seen that the glucose level does not come down to the basal level after injecting an amount of 337 $\mathrm{mg} / \mathrm{dl}$ of glucose inside a diabetic patient. The graph shows that the level of the glucose inside a diabetic patient decreases for almost the first 100 minutes and starts increasing afterward and reaches the value of almost 310 $\mathrm{mg} / \mathrm{dl}$ after 3 hours from the time the glucose was injected [34]. The goal is to bring down the value of the glucose inside a diabetic patient to the normal level. That goal can be achieved by designing a feedback controller. The controller is to regulate the infusion rate and inject the required amount of the insulin inside the diabetic patient. In turn the insulin will work inside the patient to bring down the glucose to the normal level or at least to its neighborhood.

\section{REVIEW ON GAIN-SCHEDULED PID CONTROLLERS}

The general form of the state space is defined in the following equation

$$
\begin{aligned}
& \dot{x}=A x+B u \\
& y=C x+D u
\end{aligned}
$$

where
$x:$ is the state vector
$y:$ is the output vector
$u$ : is the control vector
$A:$ is the state matrix
$B:$ is the control matrix
$C:$ is the output matrix
$D:$ is the direct transmission matrix

The proposed mathematical model (3), can be linearized at the equilibrium point $\left(x_{0}, u_{0}\right)$ and then the linearized system can be written in the state space form as

$$
\begin{aligned}
& \dot{x}=\left[\begin{array}{ccrr}
-P_{1}-x_{20} & -x_{10} & 0 & 0 \\
0 & -P_{2} & P_{3} & 0 \\
\gamma t & 0 & -n & 1 \\
0 & 0 & 0 & -\frac{1}{a}
\end{array}\right] x+\left[\begin{array}{l}
0 \\
0 \\
0 \\
\frac{1}{a}
\end{array}\right] u \\
& y=\left[\begin{array}{llll}
1 & 0 & 0 & 0
\end{array}\right] x
\end{aligned}
$$

The data of a diabetic person shown in section 2 was used and the equilibrium point $\left(x_{0}, u_{0}\right)$ was calculated as time varies from $t=1 \mathrm{~min}$ to $t=182 \mathrm{~min}$. The controllability and observability test was performed and the system was found to be controllable and observable

\subsection{Design of PID Regime-Switching Controllers for Diabetic Patient}

The patient dynamic system was expressed in the state space representation as in (6). For an overshoot less than $10 \%$, a damping ratio must be greater than 0.59 . A settling time less than 60 minutes implies that $\zeta \omega_{n}$ must be greater than 0.067 [34]. When simulating the output of the system, the glucose level, as time $t$ goes from 0 to 182 minutes, it was noted from the graphs that the output of the system can be grouped into eight groups. These groups are at the following operating points: $t=1,20,40,60,90,120,150$ and 182 minutes. The design of the PID controller was done by applying the root locus method at these operating points. The parameters $\boldsymbol{K}_{p}, \boldsymbol{K}_{i}$, and $\boldsymbol{K}_{\boldsymbol{d}}$ of the PID at each operating points are shown in Table 2 [34]. 


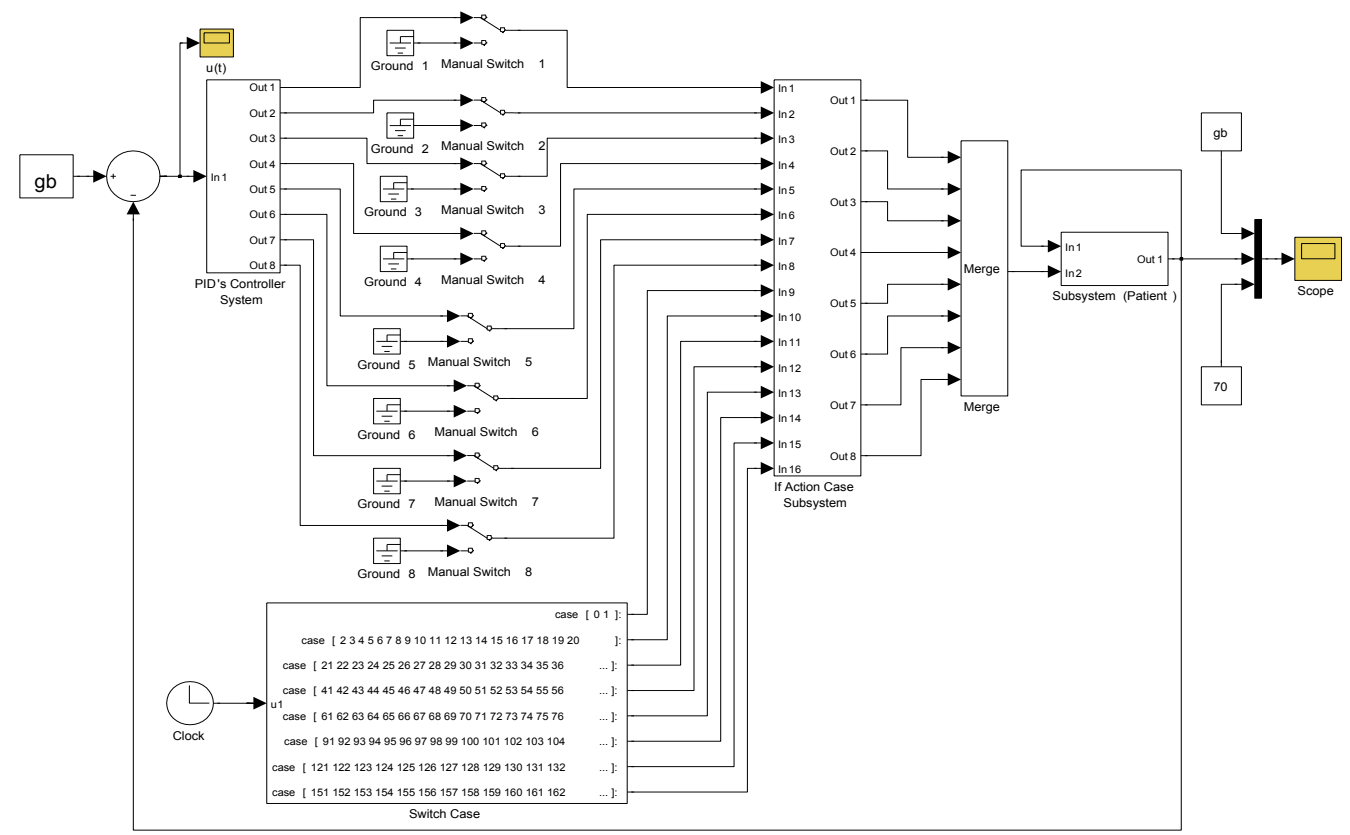

Fig. (2). Regime-switching control scheme wiring diagram using PID controllers.

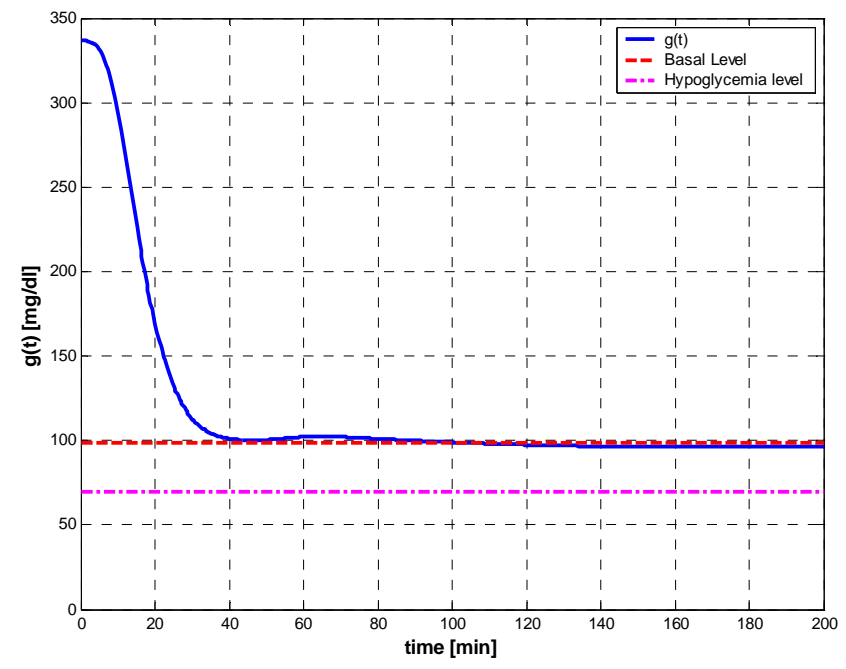

Fig. (3). Plot of glucose level $g(t)$ when only PID Controllers $g_{C}^{1}, g_{C}^{20}, g_{C}^{40}$ and $g_{C}^{60}$ are executed.

Under the individual PID controllers, the output $g(t)$, the glucose level, did not meet the design specification, and the glucose level is not near the neighborhood of the glucose basal level. The overshoot of the system is too high and beyond the acceptable level. Also the settling time was not even close to where it should be as per the design requirement. The steady state error is not satisfactory. Consequently, a new control-switching scheme was introduced that adapts controllers to meet design specifications. The wiring diagram of the regime-switching control scheme is shown in Fig. (2) [34]. The regime switching control scheme diagram was simulated with all PID controllers executed (connected to the circuit). The glucose level did not meet the design specification and went below the minimum of the glucose level [34]. In this case the person will be classified as a patient with hypoglycemia. When the control scheme was simulated with only PID controllers $g_{C}^{1}, g_{C}^{20}, g_{C}^{40}$ and $g_{C}^{60}$ are executed, the output $g(t)$ of the system reaches the glucose basal level $(99 \mathrm{mg} / \mathrm{dl})$ within 40 minutes, and it stays in that neighborhood as shown in Fig. (3) [34].

Based on the simulation results, although adaptive control can potentially improve control performance, it is sometimes unnecessary, or even harmful when switching is conducted overly frequently. In comparison to individual controllers, the regime-switching control scheme achieves design specification while all individual controllers fail to deliver the required performance [34]. As a result, it is desirable to investigate simpler and more robust control strategies.

\section{OBSERVER-BASED STATE FEEDBACK DESIGN}

The state feedback design can be designed on the basis of the pole placement method. In the pole placement method the closed loop poles will be placed at desired locations [35]. While this is similar to root-locus method used in the PID 
design, the main difference is that in the root-locus method only the dominant closed loop poles will be placed at the desired locations, while in the pole-placement method all the closed loop poles will be placed at desired locations.

\subsection{Design of State Feedback Controllers by Pole Placement for Linear Systems}

When designing a controller by the pole placement method, the designer must define the specifications that need to be achieved by the controller. The objective is to design a state feedback controller so that the closed-loop system has the following specifications: a small steady-state error under a step input; less than $10 \%$ overshoot; a settling time less than 60 minutes. We shall choose the control signal to be

$u=-K x$

This means that the control signal $u$ is determined by an instantaneous state feedback. Such a scheme is well known as state feedback. The $1 \times n$ matrix $\boldsymbol{K}$ is the state feedback gain matrix. Substituting equation (7) into equation (5), the state equation becomes

$\dot{x}=(A-B K) x$

The stability and the transient response characteristics are determined by the eigenvalues of matrix $A-B K$. The eigenvalues of matrix $A-B K$ are called the regular poles. If these poles are placed in the left half $s$ plane, then $x(t)$ approaches zero as $t$ approaches infinity. The following equation is called Ackermann's Formula used to determine the value of the matrix $K$ [35], see the appendix for derivation:

$K=\left[\begin{array}{llll}0 & 0 & 0 & 1\end{array}\right]\left[\begin{array}{llll}B & A B & A^{2} B & A^{3} B\end{array}\right]^{-1} \phi(A)$

where the matrix $K=\left[\begin{array}{llll}K_{1} & K_{2} & K_{3} & K_{4}\end{array}\right]$

The desired poles of the controller can be determined based on the damping ratio $\zeta$ and natural frequency $\omega_{n}$. The damping ratio and the natural frequency are related to the maximum overshoot, $M_{p}$, and the settling time, $t_{s}$, with the following relations

$$
M p=e^{-\frac{\pi \zeta}{\sqrt{1-\xi^{2}}}} \text { and } t_{s}=\frac{4}{\zeta \omega_{n}}
$$

Equations (10) can be rearranged to obtain the value of $\zeta$ and the natural frequency $\omega_{n}$

$$
\zeta=\sqrt{\frac{\left(\frac{\ln \left(M_{p}\right)}{\pi}\right)^{2}}{1+\left(\frac{\ln \left(M_{p}\right)}{\pi}\right)^{2}}}
$$

and $\omega_{n}=\frac{4}{\zeta t_{S}}$

The dominant poles are calculated by
$P_{1,2}=-\omega_{n} \zeta \pm j \omega_{n} \sqrt{1-\zeta^{2}}$

And the remaining two poles are chosen as

$P_{3,4}=2 P_{1,2}$

By using the data given in section 2 for a diabetic patient, maximum overshoot at $10 \%$, and settling time at 60 minutes, the damping ratio $\zeta$ and the natural frequency $\omega_{n}$ are calculated by using equation (11) as

$\zeta=0.5912$, and $\omega_{n}=0.1128$

The values of the desired poles can be calculated using equations (12) and (13)

$$
\begin{aligned}
P_{1} & =-(0.1128)(0.5912)+j(0.1128) \sqrt{1-(0.5912)^{2}} \\
& =-0.0667+j 0.091 \\
P_{2} & =-(0.1128)(0.5912)-j(0.1128) \sqrt{1-(0.5912)^{2}} \\
& =-0.0667-j 0.091 \\
P_{3} & =2(-0.0667+j 0.091)=-0.1333+j 0.1819 \\
P_{4} & =2(-0.0667-j 0.091)=-0.1333-j 0.1819
\end{aligned}
$$

Using Ackermann's Formula, the state feedback controllers can be designed based on the models at different operating points. The following are the models at $t=1,20$, $40,60,90,120,150$ and 182 minutes, and the corresponding feedback controllers. Since $B$ and $C$ do not change with time, they are fixed in all cases as:

$B=\left[\begin{array}{l}0 \\ 0 \\ 0 \\ 0.5\end{array}\right]$ and $C=\left[\begin{array}{llll}1 & 0 & 0 & 0\end{array}\right]$

The following are the matrix $A$ and corresponding matrix $K$ at certain operating points:

$\mathrm{t}=1$ minute:

$A_{1}=\left[\begin{array}{lccr}0 & -859.6667 & 0 & 0 \\ 0 & -0.0081 & 0.00000401 & 0 \\ 0.0024 & 0 & -0.23 & 1 \\ 0 & 0 & 0 & -0.5\end{array}\right]$

$K_{1}=\left[\begin{array}{llll}-0.4 & 4702.2 & 0.1 & -0.7\end{array}\right]$

$\mathrm{t}=20$ minutes:

$A_{20}=\left[\begin{array}{lccr}0 & -131.33 & 0 & 0 \\ 0 & -0.0081 & 0.000004010 & 0 \\ 0.048 & 0 & -0.23 & 1 \\ 0 & 0 & 0 & -0.5\end{array}\right]$

$K_{20}=\left[\begin{array}{llll}-2.5 & 4693.8 & 0.1 & -0.7\end{array}\right]$

$\mathrm{t}=40$ minutes:

$A_{40}=\left[\begin{array}{lccr}0 & -112.17 & 0 & 0 \\ 0 & -0.0081 & 0.00000401 & 0 \\ 0.096 & 0 & -0.23 & 1 \\ 0 & 0 & 0 & -0.5\end{array}\right]$

$K_{40}=\left[\begin{array}{llll}-2.9 & 4684.8 & 0.1 & -0.7\end{array}\right]$ 

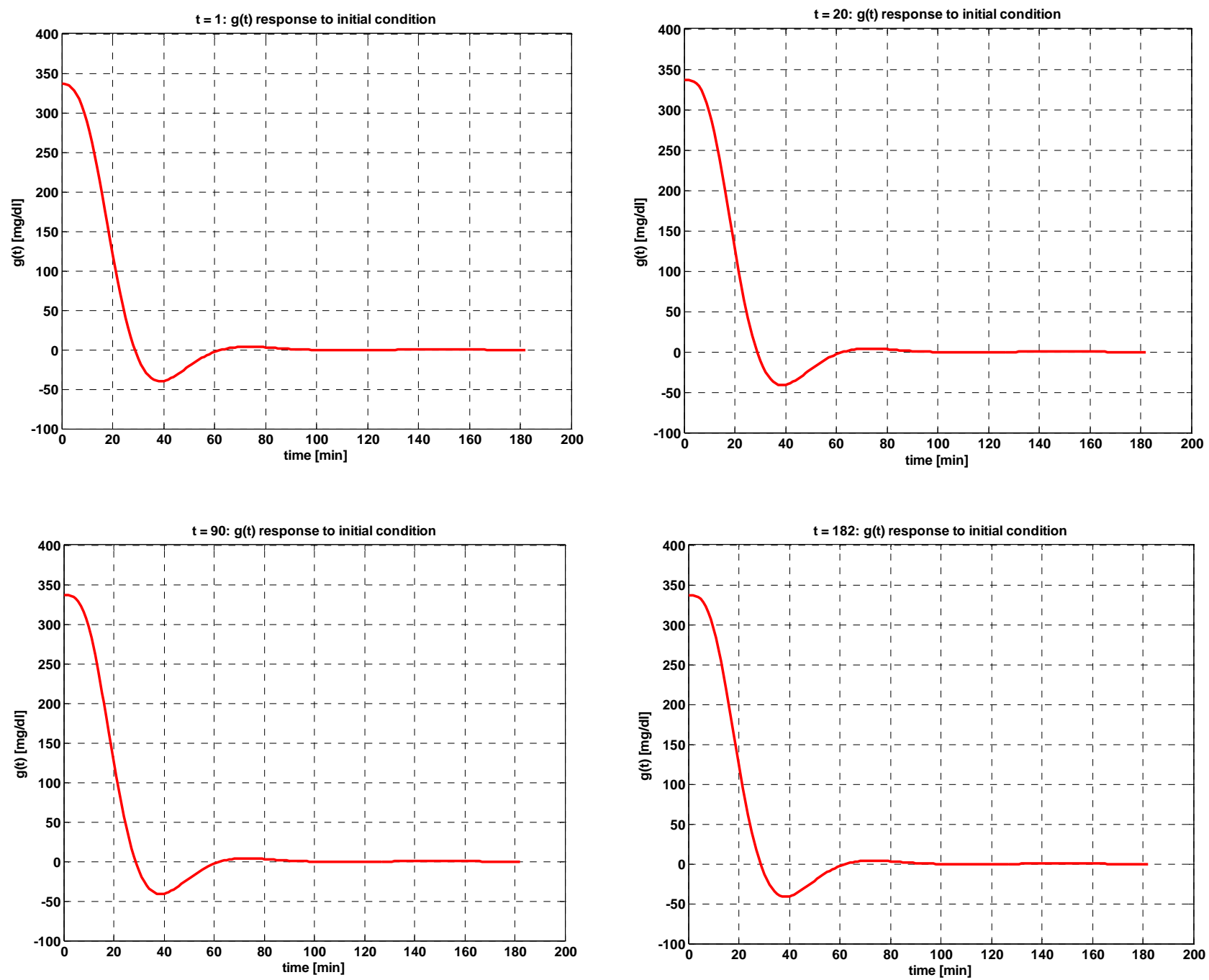

Fig. (4). Response curves to initial conditions at operating points $t=1,20,90$ and 182 minutes.

$\mathrm{t}=60$ minutes:

$A_{60}=\left[\begin{array}{lccr}0 & -105.78 & 0 & 0 \\ 0 & -0.0081 & 0.00000401 & 0 \\ 0.1440 & 0 & -0.23 & 1 \\ 0 & 0 & 0 & -0.5\end{array}\right]$

$K_{60}=\left[\begin{array}{llll}-3.0 & 4675.9 & 0.1 & -0.7\end{array}\right]$

$\mathrm{t}=90$ minutes:

$A_{90}=\left[\begin{array}{lccr}0 & -101.52 & 0 & 0 \\ 0 & -0.0081 & 0.00000401 & 0 \\ 0.2160 & 0 & -0.23 & 1 \\ 0 & 0 & 0 & -0.5\end{array}\right]$

$K_{90}=\left[\begin{array}{llll}-3.1 & 4662.5 & 0.1 & -0.7\end{array}\right]$

$\mathrm{t}=120$ minutes:

$A_{120}=\left[\begin{array}{lccr}0 & -99.39 & 0 & 0 \\ 0 & -0.0081 & 0.00000401 & 0 \\ 0.288 & 0 & -0.23 & 1 \\ 0 & 0 & 0 & -0.5\end{array}\right]$

$K_{120}=\left[\begin{array}{llll}-3.2 & 4649.1 & 0.1 & -0.7\end{array}\right]$ $\mathrm{t}=150$ minute:

$A_{150}=\left[\begin{array}{lccr}0 & -98.11 & 0 & 0 \\ 0 & -0.0081 & 0.00000401 & 0 \\ 0.36 & 0 & -0.23 & 1 \\ 0 & 0 & 0 & -0.5\end{array}\right]$
$K_{150}=\left[\begin{array}{lccc}-3.2 & 4635.7 & 0.1 & -0.7\end{array}\right]$
$\mathrm{t}=182$ minute:

$$
\begin{aligned}
A_{182} & =\left[\begin{array}{lccr}
0 & -97.21 & 0 & 0 \\
0 & -0.0081 & 0.00000401 & 0 \\
0.4368 & 0 & -0.23 & 1 \\
0 & 0 & 0 & -0.5
\end{array}\right] \\
K_{182} & =\left[\begin{array}{llll}
-3.2 & 4621.4 & 0.1 & -0.7
\end{array}\right]
\end{aligned}
$$

As mentioned above, the glucose, $g(t)$, should approach zero as the time $t$ approaches infinity. After plotting the responses to initial condition at time $t=1,20,40,60,90$, 120, 150 and 182 minutes, it was noted that the graphs are very close to each others and for that reason only four graphs are shown in Fig. (4). 


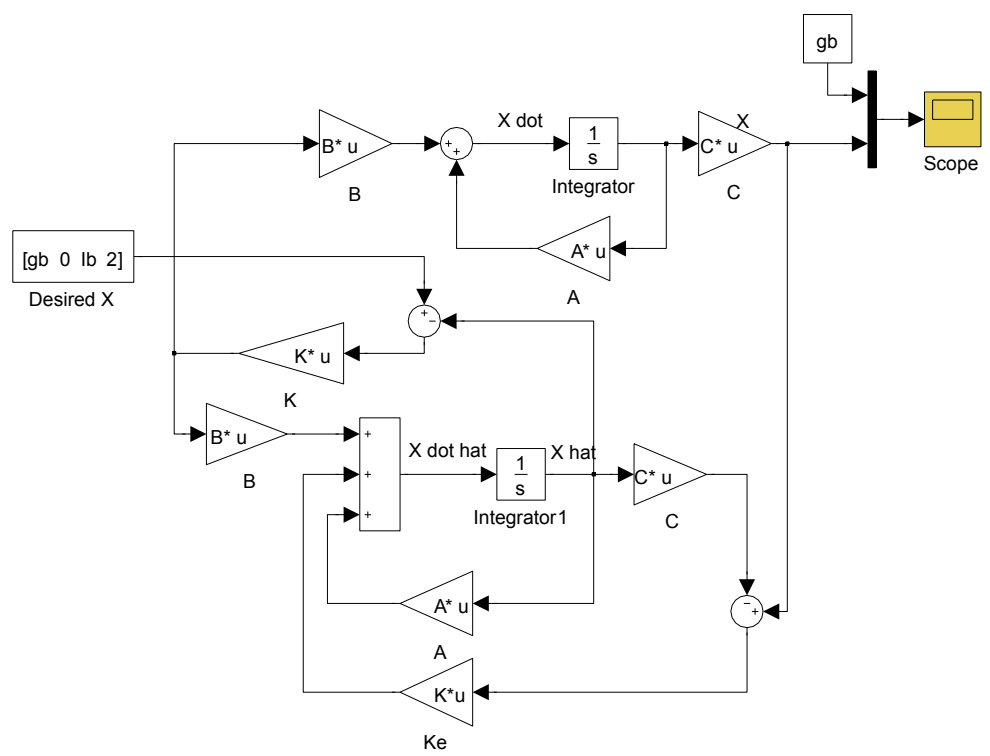

Fig. (5). Observer-based state feedback control wiring diagram.

\subsection{Design of State Observers for Linear System}

When designing a state feedback controller by the pole placement method, it is assumed that all the state variables are available for feedback. In practice the state variables may not be available for feedback. Then we need to estimate the unavailable state variables. The process of estimating the unmeasured state variables is commonly known as observation. The device that observes the estimation of the unmeasured state variables is called a state observer. The notation. The notation $x(t)$ is used to denote the observed state vector. The mathematical model of the observer is basically the same as the plant, except that we include the estimation error to compensate for inaccuracies in the initial state errors. The mathematical model of the observer is defined as

$\tilde{x}=A \tilde{x}+B u+K_{e}(y-\mathrm{C} \tilde{x})$

$u=-K \tilde{x}$

where $\tilde{x}$ is the estimated state, $C \tilde{x}$ is the estimated output and $K_{e}$ is the observer gain matrix.

Substituting equation (15) into equation (14) gives

$\tilde{x}=\left(A-K_{e} C-B K\right) \tilde{x}+K_{e} y$

The observed state variable $\tilde{x}(t)$ can be used to compute the feedback to the system. Fig. (5) shows the block diagram of the observer-based state feedback control system. The design process will be done in two phases. The first phase is to calculate the value of the feedback gain matrix $K$, and the second phase is to determine the observer gain matrix $K_{e}$. The value of the matrix $K_{e}$ is calculated by Ackermann's Formula for observers as

$$
K_{e}=\phi(A)\left[\begin{array}{l}
C \\
C A \\
C A^{2} \\
C A^{3}
\end{array}\right]^{-1}\left[\begin{array}{l}
0 \\
0 \\
0 \\
1
\end{array}\right]
$$

where the matrix

$$
K_{e}=\left[K_{e 1} K_{e 2} K_{e 3} K_{e 4}\right]^{T}
$$

Now we need to choose the observer gain $K_{e}$. Since we want the dynamics of the observer to be much faster than the system itself, we need to place the poles at least five times farther to the left than the dominant poles of the system. The values of the desired poles of the observer are selected as

$P_{o 1}=-0.3333+j 0.4548$

$P_{o 2}=-0.3333-j 0.4548$

$P_{o 3}=-0.6667+j 0.9096$

$P_{o 4}=-0.6667-j 0.9096$

The values of matrices $K$ and $K_{e}$ at certain operating points are calculated by Ackermann's method. The values of matrix $K$ were found in the previous section and the values of matrix $K_{e}$ are shown below

$\mathrm{t}=1$ minute:

$K_{e 1}=\left[\begin{array}{l}1.2620 \\ -0.0017 \\ -22.4977 \\ -58.8582\end{array}\right]$

$\mathrm{t}=40$ minutes:

$K_{e 40}=\left[\begin{array}{l}1.2620 \\ -0.0128 \\ -172.3436 \\ -451.0869\end{array}\right]$

$\mathrm{t}=90$ minutes:

$K_{e 90}=\left[\begin{array}{l}1.2620 \\ -0.0141 \\ -190.3134 \\ -498.4084\end{array}\right]$ $\mathrm{t}=20$ minutes:

$K_{e 20}=\left[\begin{array}{l}1.2620 \\ -0.0109 \\ -147.2340 \\ -385.2770\end{array}\right]$

$\mathrm{t}=60$ minutes:

$K_{e 60}=\left[\begin{array}{l}1.2620 \\ -0.0135 \\ -182.7124 \\ -478.3364\end{array}\right]$

$\mathrm{t}=120$ minutes:

$K_{e 120}=\left[\begin{array}{l}1.2620 \\ -0.0144 \\ -194.3246 \\ -509.0897\end{array}\right]$ 

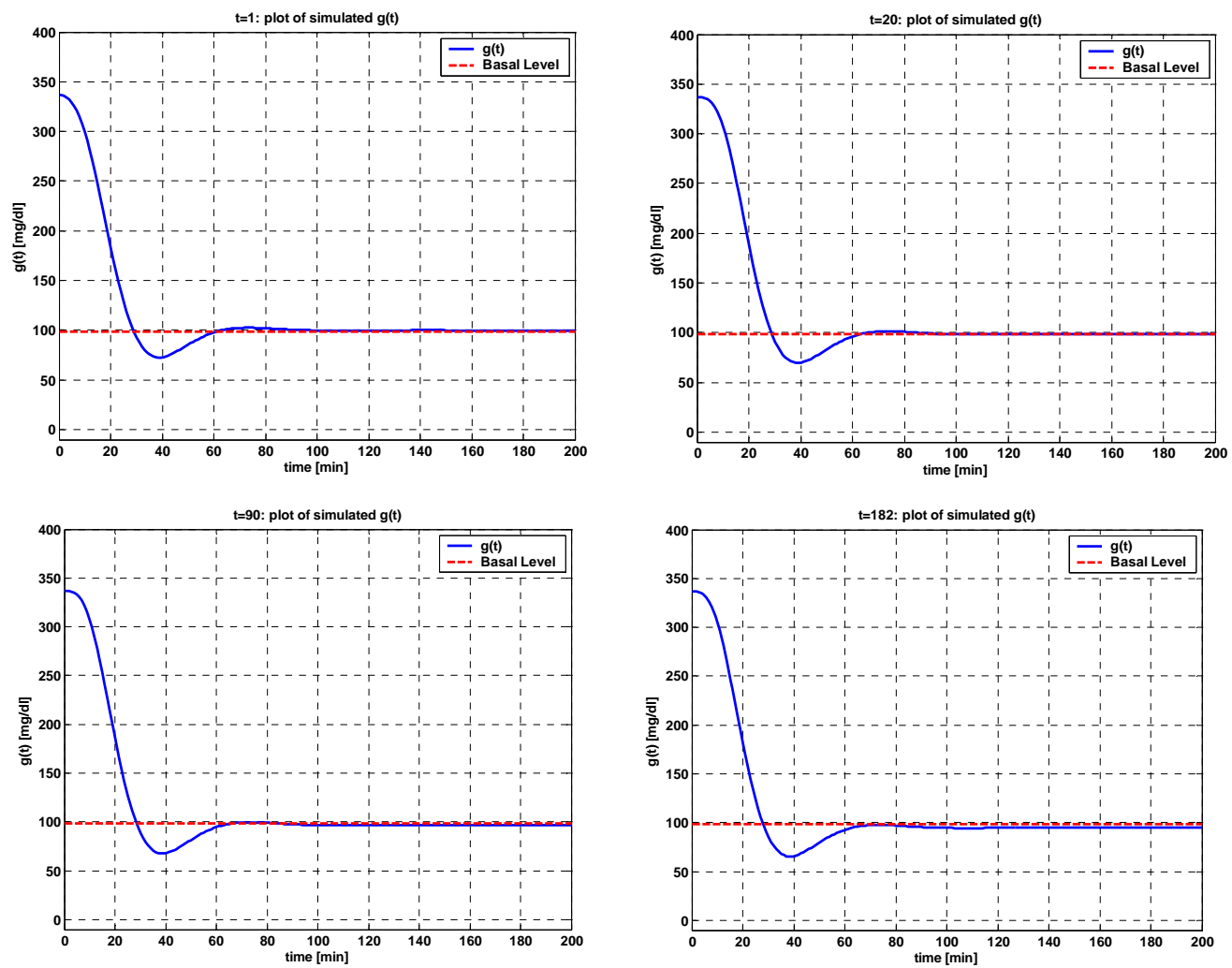

Fig. (6). Observer-based state feedback controller output, glucose level $g(t)$, at operating points $t=1,20,90$ and 182 minutes.

$\mathrm{t}=150$ minutes:

$K_{e 150}=\left[\begin{array}{l}1.2620 \\ -0.0146 \\ -196.7916 \\ -515.7316\end{array}\right]$

$$
K_{e 182}=\left[\begin{array}{l}
1.2620 \\
-0.0147 \\
-198.5401 \\
-520.5064
\end{array}\right]
$$$$
\mathrm{t}=182 \text { minutes: }
$$

\subsection{Individual Observer-Based State Feedback Controllers}

Non-adaptive observer-based state feedback controllers use a fixed controller for the entire control period and rely on its robustness to maintain control performance. For each individual observer-based state feedback controller (with its gain matrices $K$ and $K_{e}$ found in the previous sections for $t=$ $1,20,40,60,90,120,150$ and $182 \mathrm{~min}$ ), the simulation was performed and the output of the system was plotted. Based on the simulation results, it can be seen that under the individual observer state feedback controllers, the output $g(t)$, the glucose level, reaches the basal level within 60 minutes and stays at that level. By carefully analyzing the plots of the output, it is clear that the optimal graph is when the observer-based state feedback controller at time $t=20$ minutes is used. It was noted that the graphs are very close to each others and for that reason only four graphs are shown in Fig. (6).

\subsection{Observer-Based State Feedback Controller for the Nonlinear System}

Applying the design for the linear system that was calculated in section 4.2 to the nonlinear system at operating point $t=20$ minutes. The simulation diagram of the nonlinear system that defines the dynamics of the diabetic

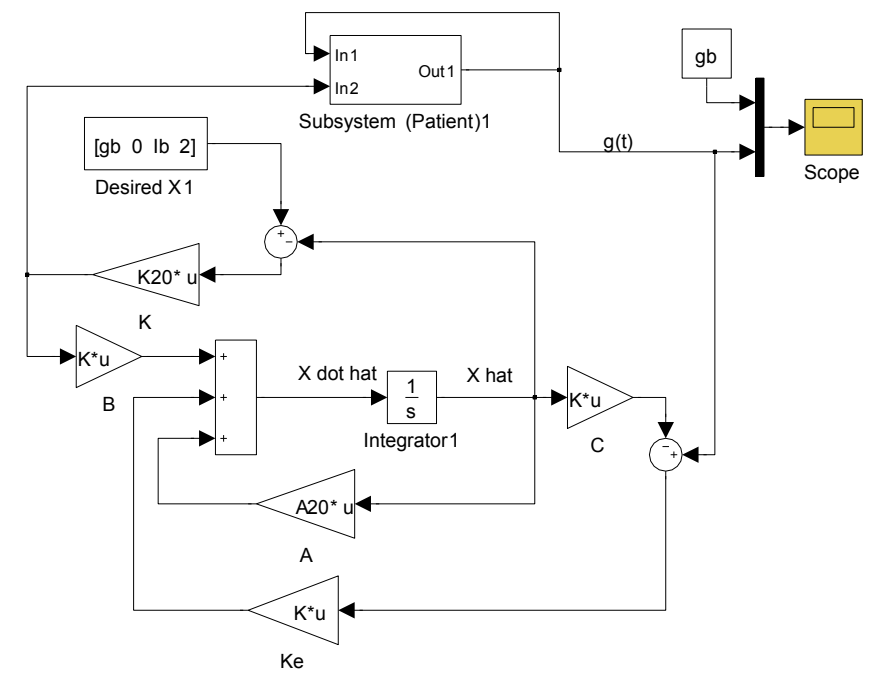

Fig. (7). Observer-based state feedback control wiring diagram for nonlinear system.

patient with the observer-based state feedback is shown in Fig. (7). The box labeled "subsystem (patient) 1" in Fig. (7) contains the nonlinear system of the diabetic patient. The simulation is performed and the glucose level $g(t)$ is plotted and shown in Fig. (8). The glucose level for the nonlinear system has the same high performance as that of the linear system.

To verify of the above design, the same control design was applied to the nonlinear system but at different maximum overshoots $1 \%, 2 \%, 3 \%, 5 \%$, and $8 \%$. The poles of the controllers and observers at operating points $t=1$, $20,40,60,90,120,150$ and 182 minutes were calculated for 


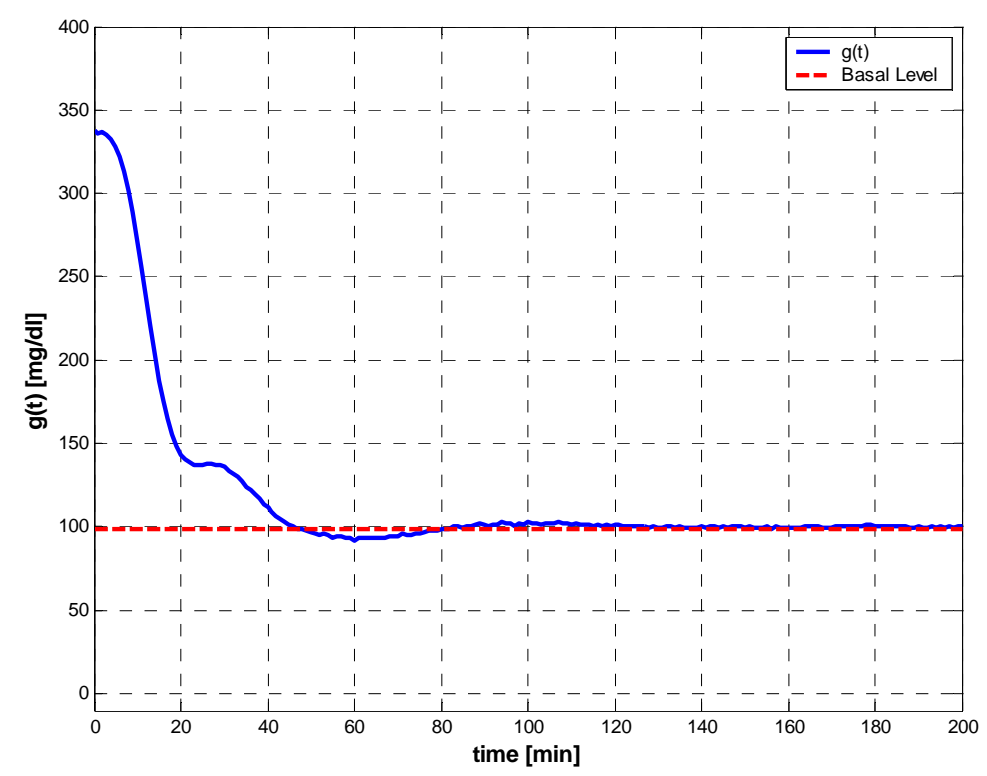

Fig. (8). Observer-based state feedback control output, glucose level $g(t)$, for nonlinear system at $t=20$ minutes.
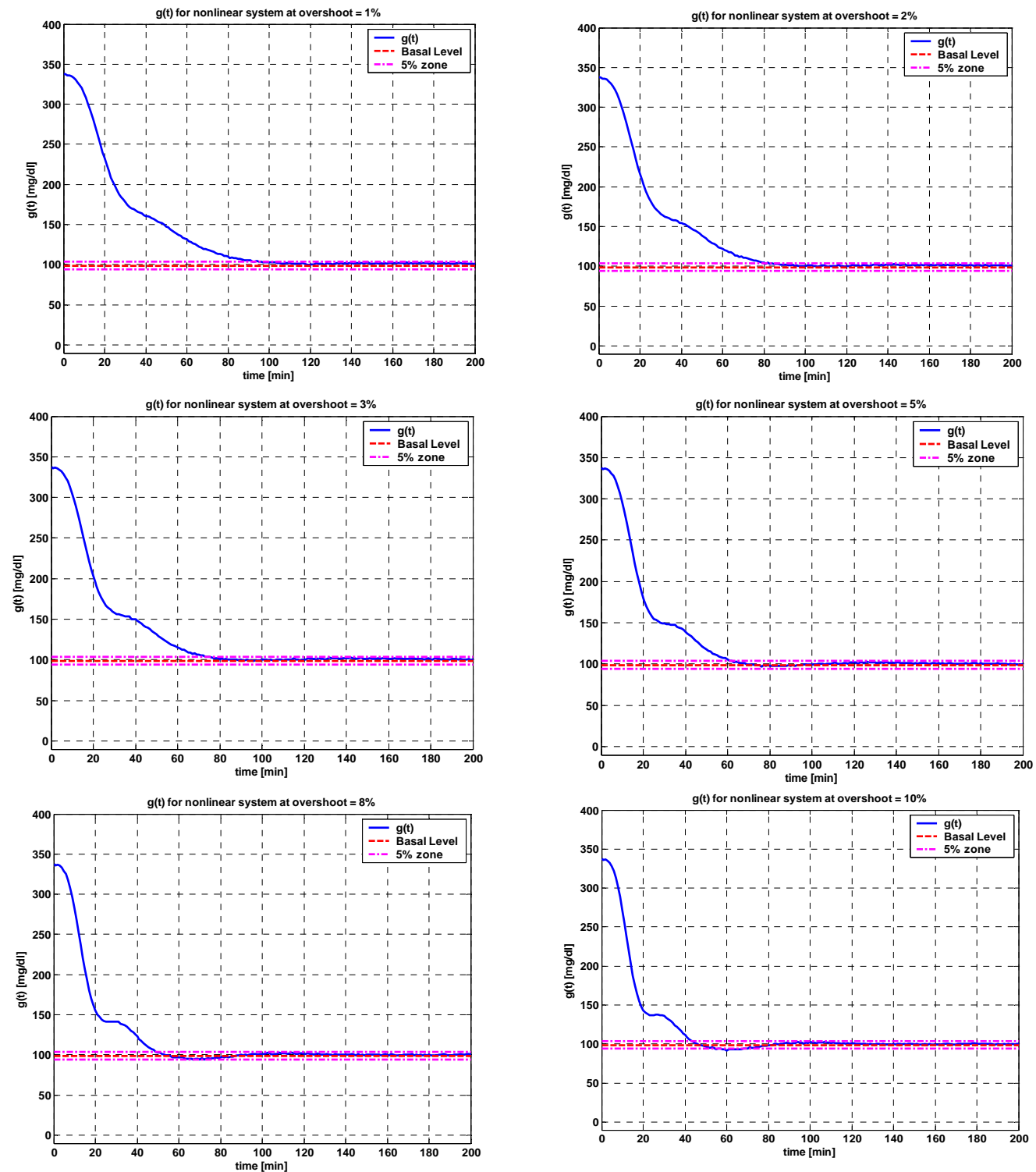

Fig. (9). Observer-based state feedback control output, glucose level $g(t)$, for nonlinear system at $t=20$ minutes for various maximum overshoots. 
Table 2. PID Controllers Parameters at Different Operating Points

\begin{tabular}{|c|c|c|c|}
\hline Time & $\boldsymbol{K}_{\boldsymbol{p}}$ & $\boldsymbol{K}_{\boldsymbol{i}}$ & $\boldsymbol{K}_{\boldsymbol{d}}$ \\
\hline \hline 1 & 0.00444 & $2.0094 \times 10^{-4}$ & 5.59 \\
\hline 20 & 0.21600 & 0.0031 & 32.70 \\
\hline 40 & 0.23740 & 0.0061 & 35.90 \\
\hline 60 & 0.24830 & 0.0095 & 36.40 \\
\hline 90 & 0.23310 & 0.0138 & 37.90 \\
\hline 120 & 0.22340 & 0.0187 & 37.70 \\
\hline 150 & 0.20320 & 0.0229 & 38.50 \\
\hline
\end{tabular}

Table 3. Glucose Level Steady State Zone Settling Times

\begin{tabular}{|c|c|c|}
\hline $\begin{array}{c}\text { Percentage } \\
\text { Maximum } \\
\text { Overshoot }\end{array}$ & $\begin{array}{c}\text { Time to Enter } \\
\text { Steady State Zone } \\
\text { (min) }\end{array}$ & $\begin{array}{c}\text { Time to Reach } \\
\text { Steady State } \\
\text { (min)) }\end{array}$ \\
\hline \hline 1 & 95 & 110 \\
\hline 2 & 82 & 100 \\
\hline 3 & 75 & 80 \\
\hline 5 & 61 & 72 \\
\hline 8 & 49 & 55 \\
\hline 10 & 44 & 47 \\
\hline
\end{tabular}

each maximum overshoot, and the glucose levels were plotted. The graphs show that the best result is when using the observer-based state feedback controller at operating point $t=20$ minutes, which was the same result that was concluded in section 4.3. Fig. (9) shows the graphs of the glucose level, $g(t)$, and the steady state zone at operating point $t=20$ minutes at various maximum overshoot values. The steady state zone is defined to be within $5 \%$ of the basal level, (94 mg/dl to $104 \mathrm{mg} / \mathrm{dl})$. The graphs were compared to each other to determine the time it takes the glucose level, $g(t)$, to enter the steady state zone. The comparison results are listed in Table $\mathbf{3}$.

By comparing the result of Table 3 and the graphs of Fig. (9), it is obvious to conclude when the maximum overshoot is small, the settling time, (the time it takes the glucose level to enter the steady state zone and to stay inside that zone), is long. But when the maximum overshoot is large, the settling time is short.

\section{CONCLUSIONS}

This study shows that typical PID controllers may not be sufficient to meet the design specification of the glucose level control problems. This is mainly due to the nonlinear nature of patient dynamic models and limited robustness of the PID controllers. An adaptive control that switches controllers based on operating conditions can potential enhance control performance. However, the switching control scheme must be carefully designed to ensure that the control specifications are met. Our results show that when the switching scheme is limited to the first four PID controllers, the performance is in fact enhanced [34].
On the other hand, in comparison to individual observerbased state feedback controllers, the glucose level reaches the basal level and the design specifications were met by using only one controller at operating point $t=20$ minutes, (see Fig. 8). In comparing with the PID controller, the PID control-switching scheme achieves the design specifications by using the first four PID controllers at operating point $t=$ 1, 20, 40 and 60 minutes, (see Fig. 3).

Also this paper investigates the output of the observerbased state feedback controller with various overshoots and compares the result. As it can be seen from Table $\mathbf{3}$, the smaller the overshoot the longer it takes for the glucose level to reach the steady state. From the above study we can conclude that the observer-based state feedback controller can give a better performance than the adaptive PID controller. From the control point of view and the complexity of the design, the observer-based state feedback controller is simpler and the design is less complex, compared with the PID regime-switching controllers. It was noted the graphs of the output of the PID regime-witching controllers, (see Fig. 3), and the observer-based state feedback, (see Fig. 8), give a similar high performance and meet the design specification. However, the observer-based state feedback reduces the complexity of the control circuit. The control components such as the "switching case", the "if action case system", the "8-intput-1-output merge" block, and the eight manual switches are eliminated when the observer-based state feedback is used and that eliminates the switching strategy that is required in the PID design. Also the PID design requires four controllers while the observerbased state feedback design requires only one controller which reduces the cost to build up the control circuit. 


\section{APPENDIX}

\section{Ackermann's Formula Derivation}

Let the desired closed loop poles be:

$s=\mu_{1}, s=\mu_{2}, s=\mu_{3}$, and $s=\mu_{4}$.

The desired characteristic equation is

$|S I-A+B K|=\left(s-\mu_{1}\right)\left(s-\mu_{2}\right)\left(s-\mu_{3}\right)\left(s-\mu_{4}\right)=s^{4}+\alpha_{1} s^{3}+\alpha_{2} s^{2}+\alpha_{3} s+\alpha_{4}=0(\mathrm{I})$

Let $\tilde{A}=A-B K$ and substituting it in equation (I)

$|s I-\tilde{A}|=s^{4}+\alpha_{1} s^{3}+\alpha_{2} s^{2}+\alpha_{3} s+\alpha_{4}=0$

The Cayley-Hamilton theorem states that $\tilde{A}$ satisfies its characteristic equation as

$\phi(\tilde{A})=\tilde{A}^{4}+\alpha_{1} \tilde{A}^{3}+\alpha_{2} \tilde{A}^{2}+\alpha_{3} \tilde{A}+\alpha_{4} I=0$

Recall the following matrix identities:

$I=I$

$\tilde{A}=A-B K$

$\tilde{A}^{2}=(A-B K)^{2}=A^{2}-A B K-B K \tilde{A}$

$\tilde{A}^{3}=(A-B K)^{3}=A^{3}-A^{2} B K-A B K \tilde{A}-B K \tilde{A}^{2}$

$\tilde{A}^{4}=(A-B K)^{4}=A^{4}-A^{3} B K-A^{2} B K-A B K \tilde{A}-B K \tilde{A}^{2}-B K \tilde{A}^{3}$

Now substituting equation (IV) in equation (III)

$$
\begin{aligned}
\phi(\tilde{A})= & A^{4}-A^{3} B K-A^{2} B K-A B K \tilde{A}-B K \tilde{A}^{2}-B K \tilde{A}^{3}+ \\
& \alpha_{1}\left(A^{3}-A^{2} B K-A B K \tilde{A}-B K \tilde{A}^{2}\right)+ \\
& \alpha_{2}\left(A^{2}-A B K-B K \tilde{A}\right)+\alpha_{3}(A-B K)+\alpha_{4} I \\
= & A^{4}-A^{3} B K-A^{2} B K-A B K \tilde{A}-B K \tilde{A}^{2}-B K \tilde{A}^{3}+ \\
& \alpha_{1} A^{3}-\alpha_{1} A^{2} B K-\alpha_{1} A B K \tilde{A}-\alpha_{1} B K \tilde{A}^{2} \\
& \alpha_{2} A^{2}-\alpha_{2} A B K-\alpha_{2} B K \tilde{A}+\alpha_{3} A-\alpha_{3} B K+\alpha_{4} I
\end{aligned}
$$

The minimal polynomial of the matrix $A$ is defined in the equation below

$$
\phi(A)=A^{4}+\alpha_{1} A^{3}+\alpha_{2} A^{2}+\alpha_{3} A+\alpha_{4} I
$$

After substituting equation (VI) in equation (V) and rearranging its terms as

$$
\begin{aligned}
\phi(\tilde{A}) & =\phi(A)-A^{3} B K-A^{2} B K-A B K \tilde{A}-B K \tilde{A}^{2} \\
& -B K \tilde{A}^{3}-\alpha_{1} A^{2} B K-\alpha_{1} A B K \tilde{A}-\alpha_{1} B K \tilde{A}^{2}-\alpha_{2} A B K-\alpha_{2} B K \tilde{A}-\alpha_{3} B K
\end{aligned}
$$

Since $\phi(\tilde{A})=0$, equation (VII) can be written as

$$
\begin{aligned}
\phi(A)= & B\left(K \tilde{A}^{3}+K \tilde{A}^{2}+\alpha_{1} K \tilde{A}^{2}+\alpha_{2} K \tilde{A}+\alpha_{3} K\right)+ \\
& A B\left(\alpha_{1} K \tilde{A}+\alpha_{2} K+K \tilde{A}\right)+A^{2} B\left(K+\alpha_{1} K\right)+A^{3} B(K)
\end{aligned}
$$

Equation (VIII) can be rearranged as
$\phi(A)=\left[\begin{array}{llll}B & A B & A^{2} B & A^{3} B\end{array}\right] \times\left[\begin{array}{c}K \tilde{A}^{3}+K \tilde{A}^{2}+\alpha_{1} K \tilde{A}^{2}+\alpha_{2} K \tilde{A}+\alpha_{3} K \\ \alpha_{1} K \tilde{A}+\alpha_{2} K+K \tilde{A} \\ K+\alpha_{1} K \\ K\end{array}\right]$ (IX)

Multiplying both sides of equation (IX) by $\left[\begin{array}{llll}B & A B & A^{2} B & A^{3} B\end{array}\right]^{-1}$ yields

$\left[\begin{array}{llll}B & A B & A^{2} B & A^{3} B\end{array}\right]^{-1} \phi(A)=\left[\begin{array}{c}K \tilde{A}^{3}+K \tilde{A}^{2}+\alpha_{1} K \tilde{A}^{2}+\alpha_{2} K \tilde{A}+\alpha_{3} K \\ \alpha_{1} K \tilde{A}+\alpha_{2} K+K \tilde{A} \\ K+\alpha_{1} K \\ K\end{array}\right](\mathrm{X})$

After multiply both sides of equation $(\mathrm{X})$ by $\left[\begin{array}{llll}0 & 0 & 0 & 1\end{array}\right]$, we obtain

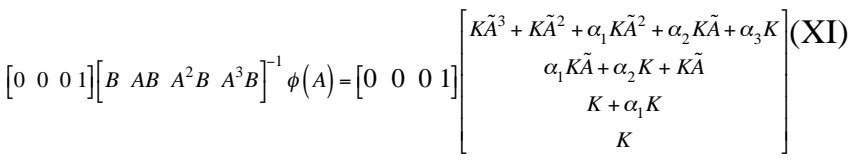

Equation (XI) is the can be written as

$K=\left[\begin{array}{llll}0 & 0 & 0 & 1\end{array}\right]\left[\begin{array}{llll}B & A B & A^{2} B & A^{3} B\end{array}\right]^{-1} \phi(A)$

where the matrix $K=\left[K_{1} K_{2} K_{3} K_{4}\right]$

Equation (XII) called Ackermann's Formula.

\section{ACKNOWLEDGEMENT}

None declared.

\section{CONFLICT OF INTEREST}

None declared.

\section{REFERENCES}

[1] J. H. Karam, G. M. Grodsky, and P. H. Forsham, "Excessive insulin response to glucose in obese subjects as measured by immunochemical assay", Diabetes, vol. 12, pp. 196-204, 1963.

[2] H. Ginsberg, J. M. Olefsky, and G. M. Reaven, "Further evidence that insulin resistance exists in patients with chemical diabetes", Diabetes, vol. 23, pp. 674-678, 1974.

[3] G.M. Reaven, and J. M. Olefsky. "Relationship between heterogeneity of insulin responses and insulin resistance in normal subjects and patients with chemical diabetes", Diabetologia, vol. 13, pp. 201-206, 1977.

[4] R.L. Lerner, and D. Porte Jr., "Acute and steady state insulin responses to glucose in nonobese, diabetic subjects", J. Clin. Invest., vol. 51, no. 7, pp. 1624-1631, 1972.

[5] G.M. Reaven, "Insulin-independent diabetes mellitus: metabolic characteristics', Metab. Clin. Exp., vol. 29, no. 5, pp. 445-454, 1980

[6] R.N. Bergman, and C. Cobelli. "Minimal modeling, partition analysis, and the estimation of insulin sensitivity", Fed. Proc., vol. 39 , no. 1 , pp. $110-115,1980$

[7] S.W. Shen, G. M. Reaven, and J. W. Farquhar, "Comparison of impedance to insulin-mediated glucose uptake in normal and diabetic subjects" J. Clin. Invest., vol. 49, pp. 2151-2160, 1970

[8] P. Dua, F.H Doyle III, and E.N. Pistikopoulos, " Model-Based blood glucose control for type i diabetes via parametric programming", IEEE Trans. Biomed. Eng., vol. 53, no. 8, pp. 1478 1491, 2006.

[9] N. Hernjak, and F.J. Doyle III, "Glucose control design using nonlinearity assessment techniques", AIChE J., vol. 51, no. 2, pp. 544-554, 2005. 
[10] D. Radomski, M. Lawrynczuk, P. Marusak, and P. Tatjewski, "Modeling of glucose concentration dynamics for predictive control of insulin administration" Biocybernet Biomed Eng, vol. 30, no. 1, pp. 41-53, 2010.

[11] R.N. Bergman, Y.Z. Ider, C.R. Bowden, and C. Cobelli, "Quantitative estimation of insulin sensitivity", Am. J. Physiol., vol. 236, no. 6, pp. E667-E677, 1979.

[12] G. Pacini, and R.N. Bergman, "MINMOD, A computer program to calculate insulin and pancreatic responsivity from the frequently sampled intravenous glucose tolerance test", Comput. Methods Programs Biomed., vol. 23, no. 2, pp. 113-122, 1986.

[13] R.N. Bergman, L.S. Phillips, and C. Cobelli, "Physiologic Evaluation of factors controlling glucose tolerance in man, Measurement of insulin sensitivity and $\beta$-cell glucose sensitivity from the response to intravenous glucose", J. Clin. Invest., vol. 68, no. 6 , pp. 1456-1467, 1981.

[14] R.N Bergman, and J. Urquhart, "The pilot gland approach to the study of insulin secretory dynamics", Recent Prog. Horm. Res., vol. 27, pp. 583-605, 1971.

[15] M. Nomura, M. Shichiri, R. Kawamori, Y. Yamasaki, N. Iwama, and $\mathrm{H}$. Abe, "A mathematical insulin-secretion model and its validation in isolated rat pancreatic islets perifusion", Comput. Biomed. Res., vol. 17, no. 6, pp. 570-579, 1984.

[16] T.A. Buchanan, B.E Metzger, N. Freinkel, and R.N Bergman, "Insulin sensitivity and B-cell responsiveness to glucose during late pregnancy in lean and moderately obese women with normal glucose tolerance or mild gestational diabetes", Am. J. Obstet. Gynecol., vol 162, no. 4, pp. 1008-1014, 1990.

[17] S.M. Lynch, and B.W. Bequette, "Estimation-based model predictive control of blood glucose in type i diabetics: a simulation study", IEEE. Bio. Eng. Conf., 2001, pp. 79-80.

[18] M.E. Fisher, "A semi-closed loop algorithm for the control of blood glucose levels in diabetes", IEEE. Trans Biomed. Eng., vol. 38, no. 1, pp. 57-61, 1991

[19] S.M. Furler, E.W. Kraegen, R.H. Smallwood, and D.J. Chisholm, "Blood glucose control by intermittent loop closure in the basal mode: computer simulation studies with a diabetic model", Diabetes Care, vol 8, no. 6, pp. 553- 561, 1985.

[20] M.S. Ibbini, M.A. Masadeh, and Amer, M.M.B. "A semiclosedloop optimal control system for blood glucose level in diabetics" $J$. Med. Eng. Technol., vol 28, no. 5, p.p. 189-196, 2004.

[21] P.G. Fabietti, V. Canonico, M.O. Federici, M.M. Benedetti, and E. Sarti, "Control oriented model of insulin and glucose dynamics in type i diabetics". Med. Biol. Eng. Comput., vol 44, no. 1-2, pp. 6978, 2006.

[22] P.A. Insel, J.E. Liljenquist, J.D. Tobin, R.S. Sherwin, P. Watkins, R. Andres, and M. Berman, "Insulin control of glucose metabolism in man", J. Clin. Invest., vol 5, no. 5, pp. 1057-1066, 1975.

[23] G.M. Grodsky, "A threshold distribution hypothesis for packet storage of insulin and its mathematical modeling", J. Clin. Invest., vol. 51, no. 8, pp. 2047-2059, 1972.

[24] R.S. Sherwin, K.J. Kramer, J.D. Tobin, P.A. Insel, J.E. Liljenquist, M. Berman, and R. Andres, "A model of the kinetics of insulin in man”, J. Clin. Invest., vol 53, pp. 1481-1492, 1974.

[25] R.C. Turner, R.R. Holman, D. Mathews, T. D. R. Hockaday, and J. Peto, "Insulin deficiency and insulin resistance interaction in diabetes: estimation of their relative contribution by feedback analysis from basal insulin and glucose concentrations", Metab. Clin. Exp., vol 28, no. 11, pp. 1086-1096, 1979.

[26] R.L. Lerner, and D. Porte Jr., "Relationships between intravenous glucose loads, insulin responses and glucose disappearance rate", $J$. Clin. Endocrinol. Metab., vol 33, no. 3, pp. 409-417, 1971.

[27] R. Hovorka, V. Canonico, L.J. Chassin, U. Haueter, M. MassiBenedetti, M. Orsini-Federici, T.R. Pieber, H.C. Schaller, L. Schaupp, T. Vering, and M.E. Wilinska, "Nonlinear Model predictive control of glucose concentration in subjects with type $\mathrm{i}$ diabetes", Physiol. Meas., vol. 25, no. 4, pp. 905-920, 2004.

[28] E. Liu, and J.M. Yuanet, "Dynamic sensitivity and control analyses of metabolic insulin signalling pathways", IET Sysl. Biol., vol. 4, no. 1, pp 64-81, 2010.

[29] "Blood-Sugar Chart, Health Calculators" http://www.medindia.net, October 2011.

[30] "Hypoglycemia: Low Blood Sugar Causes, Symptoms, Diagnosis, and Treatement" http://www.emedicinehealth.com, October 2011

[31] V.W. Bolie, "Coefficients of normal blood glucose regulation", $J$. Appl. Physiol., vol 16, no. 5, pp. 783-788, 1961.

[32] A.C. Guyton, and J.E. Hall, Text book of Medical Physiology, 9th ed., Saunders, 1996.

[33] "Diabetic Conversion Factors", Available at: http://www.diabetesexplained.com., 2006.

[34] A.M. Hariri, and L.Y. Wang, "Identification and low-complexity regime-switching insulin control of type i diabetic patients", $J$. Biomed. Sci. Eng., vol. 4, no. 4, pp. 297-314, 2011.

[35] K. Ogata, "Modern Control Engineering", 4th ed. Prentice Hall, 2002.

Received: September 09, 2011

Revised: October 31, 2011

Accepted: November 01, 2011

(C) Hariri and Wang; Licensee Bentham Open.

This is an open access article licensed under the terms of the Creative Commons Attribution Non-Commercial License (http://creativecommons.org/licenses/by-nc/3.0/) which permits unrestricted, non-commercial use, distribution and reproduction in any medium, provided the work is properly cited. 